\title{
Indole-3-acetic Acid (IAA) Content and Axillary Bud Development in Relation to Russet Spotting in Harvested Iceberg Lettuce
}

\author{
Mark A. Ritenour \\ Department of Vegetable Crops, Mann Laboratory, University of California, Davis, CA 95616-8631 \\ Ellen G. Sutter \\ Department of Pomology, University of California, Davis, CA 95616-8683 \\ David M. Williams \\ Eagle Research, P.O. Box 1981, Salinas CA 93902 \\ Mikal E. Saltveit \\ Department of Vegetable Crops, Mann Laboratory, University of California, Davis, CA 95616-8631 \\ Additional index words. PAL, phenylalanine ammonia-lyase, postharvest disorders, secondary metabolism
}

\begin{abstract}
This study was undertaken to determine if endogenous IAA content and axillary bud development correlate with phenylalanine ammonia-lyase (PAL) induction and russet spotting (RS) susceptibility among RS susceptible and resistant cultivars of Iceberg lettuce (Lactuca sativa L.). Final levels of ethylene-induced PAL activity and RS development were highly correlated among cultivars, field conditions, and harvest dates. Harvested Iceberg lettuce midribs contained

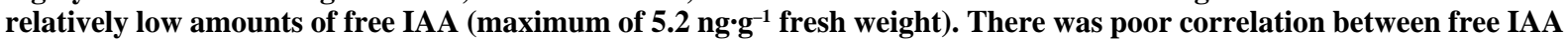
content in lettuce leaf midribs and final RS development among all cultivars, growing conditions, and harvest dates. Axillary bud development, as measured by the number of visible buds per head, bud weight, or bud length, were not significantly correlated with final RS development or midrib IAA content. Cultivars with higher initial free IAA content lost much of their IAA after 8 days storage at $5 \mathrm{C}$ in air \pm ethylene.
\end{abstract}

California produces $73 \%$ of the United States' Iceberg lettuce, with a 1993 value of $\$ 848$ million (California Dept. of Finance, 1993; U.S. Dept. of Agriculture, 1994). Russet spotting (RS) is a major physiological disorder of harvested Iceberg lettuce. RS is induced by exposure to ethylene in air at slightly elevated storage temperatures (Rood, 1956). When exposed to $10 \mu l \cdot$ liter $^{-1}$ ethylene at 5C, symptoms appear after about 3 days and are characterized by 1- to 2-mm-diameter oval brown sunken lesions on the midrib, which in advanced stages may spread over the entire leaf blade (Link and Gardner, 1919; Rood, 1956).

Hyodo et al. (1978) observed that the activity of phenylalanine ammonia-lyase (PAL), an enzyme that catalyzes the first committed step in the phenylpropanoid pathway (Camm and Towers, 1973; Koukol and Conn, 1961), increased in tissue exposed to ethylene and that the increase correlated with increased RS symptoms. The deamination of L-phenylalanine to trans-cinnamic acid by PAL leads to the formation of many phenolic secondary plant products, among which are some that are correlated with brown discoloration seen in RS. Ke and Saltveit (1989a) also observed a correlation between PAL activity and RS development when comparing RS resistant and sensitive cultivars.

Stresses before and after harvest, such as adverse temperatures, wounding, and disease, can greatly enhance or predispose even resistant lettuce cultivars to develop RS lesions (Lipton et al., 1972; Moline and Lipton, 1987; Rood, 1956). This may explain why lettuce harvested at the beginning and end of the growing season, when environmental stresses may be greatest, are more susceptible to RS (Lipton et al., 1972; Rood, 1956). Physical wounding, either before

Received for publication 25 Aug. 1995. Accepted for publication 10 Jan. 1996. We thank John Labavitch for the use of his GC-MS. The cost of publishing this paper was defrayed in part by the payment of page charges. Under postal regulations, this paper therefore must be hereby marked advertisement solely to indicate this fact. or after harvest, induces PAL activity and the accumulation of phenolic compounds, but not RS symptoms (Ke and Saltveit, 1989c). However, wounded tissue subsequently exposed to ethylene developed greater RS symptoms than nonwounded tissue. These results indicate that wounding during preparation of lightly processed lettuce could increase the potential for RS development. In addition, a clearer understanding of the regulating factors contributing to RS susceptibility may have important ramifications for predicting and modifying the severity of other browning phenomena. Low $\mathrm{O}_{2}$ and high $\mathrm{CO}_{2}$ concentrations inhibit RS development, while advanced maturity increases susceptibility (Ke and Saltveit, 1989b; Lipton, 1967; Morris et al., 1974; Rood, 1956).

Applying auxins (IAA or 2,4-D) to excised midrib tissue reduced the activities of peroxidase, IAA oxidase, and PAL; lowered the soluble phenolic content; and inhibited RS development during ethylene exposure (Ke and Saltveit, 1986; 1988). Leaves from 20-day-old Iceberg lettuce plants showed lower ethylene-induced activities of ionically bound IAA oxidase and PAL and no RS symptoms, while leaves from 100-day-old plants showed greater ionically bound IAA oxidase activity, PAL activity, and RS symptoms (Ke and Saltveit, 1989a). Further, IAA oxidase activity was higher in susceptible than in RS-resistant Iceberg cultivars. They suggested that endogenous IAA levels may modulate the susceptibility of lettuce to ethylene-induced RS development, and that IAA oxidase may be important in reducing endogenous IAA levels (Ke and Saltveit, 1988; 1989a).

Endogenous auxin plays an important role in regulating apical dominance (Hillman, 1986). However, it is unclear what influence IAA produced in the leaf has on axillary bud development (White et al., 1975). If high endogenous IAA leaf concentrations either encourage axillary bud development or promote dormancy, then axillary bud development could be a useful indicator of leaf IAA content and, thereby, RS susceptibility. 
Currently, growers can select resistant cultivars to reduce the chance of developing RS symptoms during transit. However, because even RS-resistant cultivars can develop ethylene-induced RS symptoms if they are grown under unfavorable conditions or wounded, growers and shippers of Iceberg lettuce could benefit from a method to predict RS susceptibility. Such a method should apply to a broad range of cultivars and environmental conditions.

The current study was undertaken to determine if endogenous IAA content correlates with RS susceptibility and axillary bud length, weight, and number per head. If such correlations exist, then measuring axillary bud development could provide a quick and easy method to determine the potential for RS susceptibility of lettuce cultivars grown under a wide variety of environmental conditions.

\section{Materials and Methods}

Iceberg lettuce cultivars were grown under commercial cultural practices at four fields in Salinas, Calif. Each planting was scheduled so that harvests occurred within about 2 weeks of each other during October and November. The RS-resistant cultivars used were 'El Toro' and 'Calmar' and the RS-sensitive cultivars were 'Salinas' and 'Red Coach 74' ('RC 74'). 'Calmar' and 'Salinas' were harvested from all four fields, 'El Toro' was harvested from three, and 'RC 74' was harvested from two. Harvested lettuce heads were transported to Davis, Calif., where they were held at $2.5 \mathrm{C}$ until prepared for the experiments.

Wrapper and cap leaves were removed and the next 10 to 12 whole leaves were excised and placed in 20-liter jars at 5C with flows of humidified air $\pm 10 \mu \mathrm{l} \cdot$ liter $^{-1}$ ethylene at sufficient rates to maintain $\mathrm{CO}_{2}$ levels below O. $15 \%$. Because wounding induces PAL activity in tissue up to $2.5 \mathrm{~cm}$ away from the site of wounding and enhances subsequent RS development (Ke and Saltveit, 1989c), we used whole leaves that were cut at their base and carefully separated from the head so that wounding (e.g., cracks, rips, etc.) did not occur within at least $3 \mathrm{~cm}$ of the tissue used for analysis. Ke and Saltveit (1986) reported that basal midrib tissue was most sensitive to RS. Therefore, $4 \times 3-\mathrm{cm}$ midrib segments were excised starting about $4 \mathrm{~cm}$ from the cut base and were used for PAL analysis, RS score, and IAA analysis. All visible axillary buds were excised flush with the base of the stem, counted, and weighed and their lengths measured. PAL activity and RS development were determined on days 0,4 , and 8 . At the beginning (day 0 ) and end (day 8) of the experiments, lettuce midrib tissue used for endogenous IAA quantification was scored for RS development, frozen in liquid nitrogen, lyophilized, and then stored at $-80 \mathrm{C}$ until analyzed. Preliminary studies indicated that free IAA content in midrib tissue was not significantly reduced during freeze drying or subsequent storage (data not shown).

For all measurements, two leaves were used for each replicate and each treatment had three replications. Midrib segments used for analysis were scored visually for RS symptoms using a scale of 1 (no RS) to 9 (very severe RS). PAL was assayed as described by Ke and Saltveit (1986); activity is expressed as $\mu$ mol cinnamic $\mathrm{acid} / \mathrm{g}$ fresh weight per $\mathrm{h}$.

Free endogenous IAA levels were determined using a modified procedure developed by Chen et al. (1988). All solvents were highperformance liquid chromatography (HPLC) grade. Two grams fresh weight of freeze-dried Iceberg lettuce midrib tissue was ground in their individual screw-cap bottles with a glass rod and transferred to a test tube, and extraction buffer (65\% isopropanol containing $35 \% 0.2 \mathrm{M}$ imidazole buffer, $\mathrm{pH} 7.0$ ) was added. The bottle was rinsed four times with buffer so that the total volume equaled $2 \mathrm{ml} \cdot \mathrm{g}^{-1}$ fresh tissue. An internal standard of $100 \mathrm{ng}$ of $\left[{ }^{13} \mathrm{C}_{6}\right]$ IAA (Cohen et al., 1986) was added and gently mixed. Isotopes were allowed to equilibrate with the sample for $1 \mathrm{~h}$ at $4 \mathrm{C}$ and then centrifuged at $13,000 \times \mathrm{g}$ for $5 \mathrm{~min}$. The supernatant was collected and the pellet was washed with $0.5 \mathrm{ml}$ extraction buffer and recentrifuged. The initial and wash supernatants were combined and evaporated in a rotary evaporator until all propanol was removed. The remaining aliquot was diluted with $30 \mathrm{ml}$ water to reduce imidazole concentration to about $0.02 \mathrm{~mm}$. Amino anion exchange columns (PrepSep; Fisher Scientific, Pittsburgh) were washed with hexane, acetonitrile (ACN), and water before being conditioned with $2 \mathrm{ml}$ of $0.2 \mathrm{M}$ imidazole buffer $(\mathrm{pH} \mathrm{7.0)}$ ) and washed again with $10 \mathrm{ml}$ water to remove excess buffer. The dilute extract was applied to the column and allowed to elute at $\leq 5$ $\mathrm{ml} \cdot \mathrm{min}^{-1}$ using an extraction system (J.T. Baker, Phillipsburg, N.J.). Columns were washed sequentially with $2 \mathrm{ml}$ hexane, ethylacetate, ACN, and methanol (MeOH). IAA was eluted with 3 $\mathrm{ml} \mathrm{MeOH}$ containing $2 \%$ acetic acid. The eluent was evaporated to dryness and immediately resuspended in $150 \mu \mathrm{l}$ of $30 \% \mathrm{ACN}$.

The resuspended sample was further purified using reversephase HPLC equipped with a C18 column (Phenomenex, Torrance, Calif.). A 15-min linear gradient was run from $30 \%$ to $90 \%$ ACN in water plus $0.1 \%$ acetic acid. Under these conditions the retention time of IAA was about $10 \mathrm{~min}$. IAA was detected using a fluorescence detector (Spectroflow 980; Applied Biosystems, Foster City, Calif.). The detector excitation wavelength was 220 $\mathrm{nm}$, and the emitted light was monitored using a 350-nm band path filter. Peaks eluting at the same retention time as authentic IAA were collected, evaporated to dryness, and resuspended in $200 \mu \mathrm{l}$ methanol. Samples were methylated with ethereal diazomethane as described by Cohen (1984), evaporated to dryness in a rotary evaporator under $\mathrm{N}_{2}$, and resuspended in $15 \mu$ l ethyl acetate for gas chromatography-mass spectroscopy (GC-MS) analysis. A 1- to 3$\mu \mathrm{l}$ sample was injected into a GC (model 5890A; Hewlett Packard) equipped with a $15-\mathrm{m}$ capillary column $(0.25 \mathrm{~mm}$ ID, $0.25 \mu \mathrm{m}$ film thickness) (DB-1701; J \& W Scientific, Folsom, Calif.) connected to a mass selective detector (model 5970B; Hewlett Packard). The temperature program was 140 to $240 \mathrm{C}$ at $20 \mathrm{C} / \mathrm{min}$. IAA was

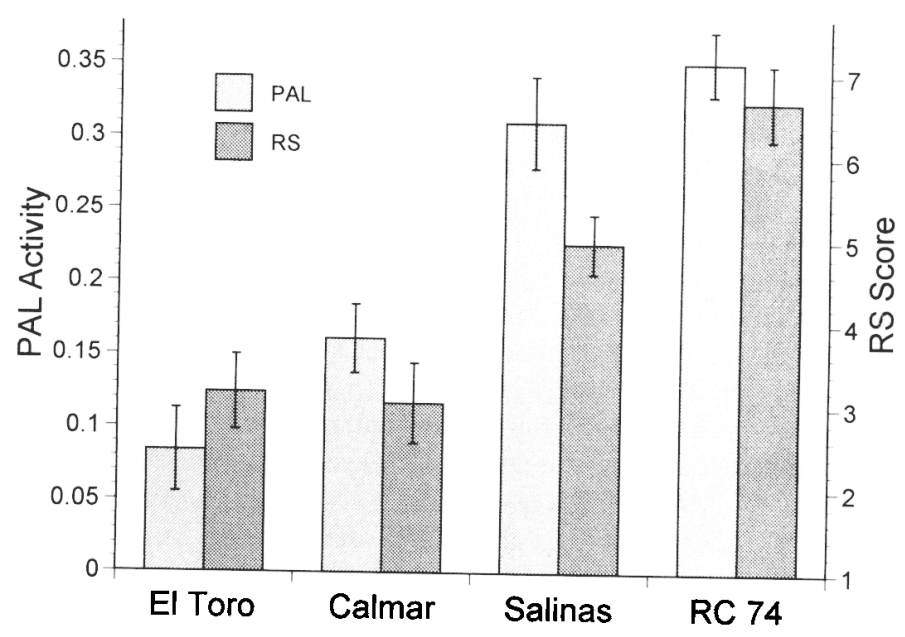

Fig. 1. PAL activity and RS development in four cultivars of Iceberg lettuce midrib segments exposed to air $+10 \mu$ liter $^{-1}$ ethylene for 8 days at $5 \mathrm{C}$. PAL activity is expressed as $\mu \mathrm{mol}$ cinnamic acid $/(\mathrm{g}$ fresh weight $/ \mathrm{h})$. Leaves were scored visually for RS using a state of $1=$ none to $9=$ very severe. The vertical bars represent standard error. 
quantified by selected ion monitoring (SIM) of $\mathrm{m} / \mathrm{z}, 130$ and 189 for authentic IAA-ME and $m / z 136$ and 195 for $\left[{ }^{13} \mathrm{C}_{6}\right] \mathrm{IAA}-\mathrm{ME}$ as described by Cohen et al., (1986).

\section{Results}

'El Toro' and 'Calmar' were relatively resistant to ethyleneinduced RS compared to 'Salinas' and 'RC 74' (Fig. 1). The two resistant cultivars developed only slight $\mathrm{RS}$ after 8 days in air +10 $\mu l \cdot$ liter $^{-1}$ ethylene at $5 \mathrm{C}$, while the two susceptible cultivars developed moderate to severe RS under the same conditions. There was no significant difference at $P=0.05$ in RS development between 'El Toro' and 'Calmar,' but 'Salinas' and 'RC 74' were both significantly higher than the RS-resistant cultivars and were significantly different from each other. After 8 days exposure to 10 $\mu l \cdot$ liter $^{-1}$ ethylene, RS resistant cultivars developed about half the RS found in 'Salinas' and only about a third of that formed in 'RC 74.' PAL activity generally paralleled RS development and was significantly lower in RS-resistant cultivars than in susceptible cultivars. Final ethylene-induced PAL activity and RS development were positively correlated $\left(R^{2}=0.82\right)$ across different cultivars, field conditions, and harvest dates.

Endogenous free IAA content was significantly higher on day 0 in 'El Toro,' 'Calmar,' and 'Salinas' than 'RC 74' (Fig. 2a). 'RC 74 ' had only about one-third of the initial IAA in the other cultivars and did not change significantly after 8 days storage in air \pm
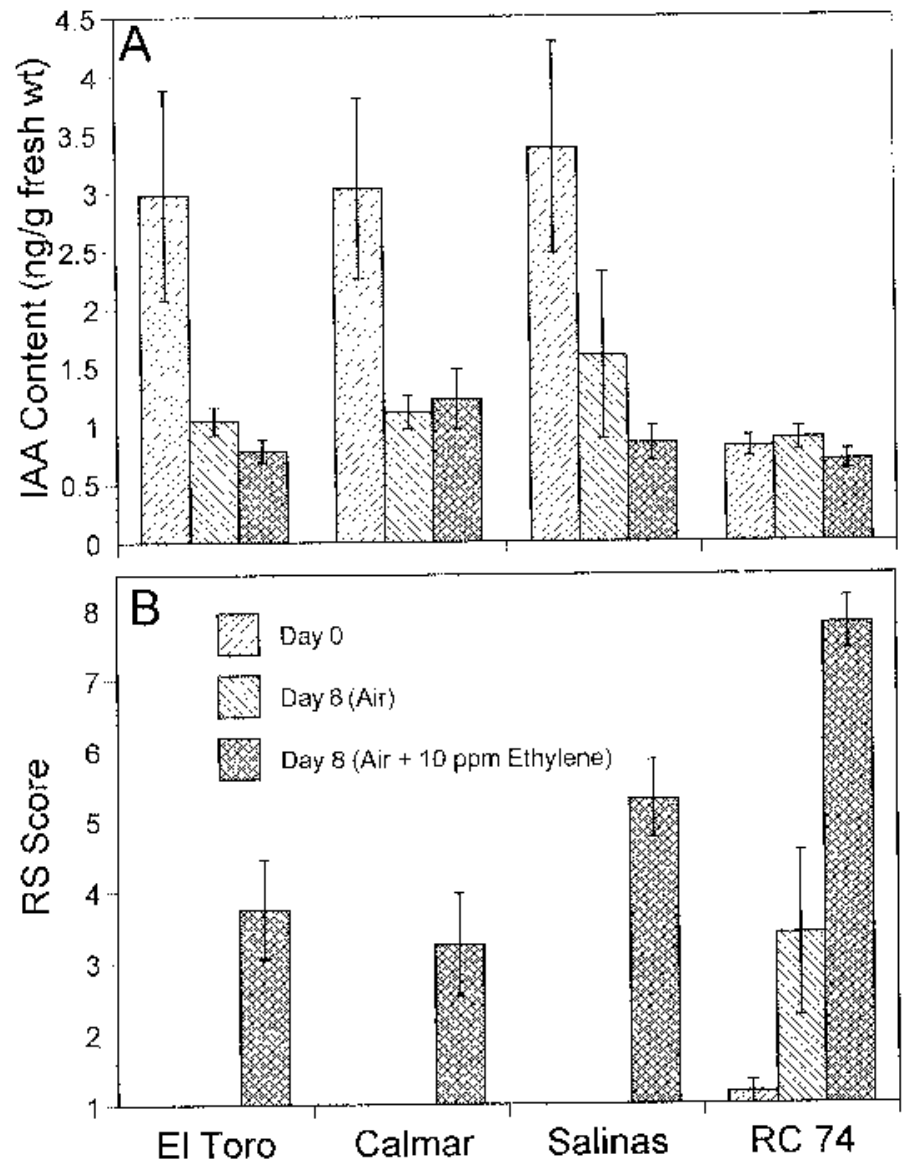

Fig. 2. Endogenous IAA content (A) and RS development (B) in four cultivars of Iceberg lettuce midrib segments stored at $5 \mathrm{C}$ with or without $10 \mu 1 \cdot$ liter $^{-1}$ ethylene for 0 or 8 days. Leaves were scored visually for RS using a scale of $1=$ none to $9=$ very severe. The vertical bars represent standard error. ethylene. The three cultivars with greater initial free IAA content lost more than half of their IAA after 8 days storage whether or not ethylene was present. There was no significant difference in IAA content among the four cultivars after 8 days of storage in air \pm ethylene.

At the beginning of the experiments, virtually no RS symptoms were present in any of the cultivars (Fig. 2b). After 8 days of storage in air, 'El Toro,' 'Calmar,' and 'Salinas' showed no RS symptoms, while 'RC 74' showed slight symptoms. After 8 days exposure to air $+10 \mu \mathrm{l} \cdot$ liter $^{-1}$ ethylene, all cultivars developed RS symptoms similar to those described in Fig. 1.

The correlation between initial endogenous IAA content and final ethylene-induced RS development was poor across cultivars, lettuce fields, and harvest dates (Fig. 3a). A log curve gave the best fit with an $R^{2}$ of only 0.50 . However, when 'Salinas' was excluded from the analysis, the $R^{2}$ increased to 0.80 (data not shown). Initial IAA content also was not significantly correlated with RS development within cultivars (data not shown). Final IAA content of lettuce stored 8 days in air \pm ethylene also did not show a significant correlation with final RS development (data not shown).

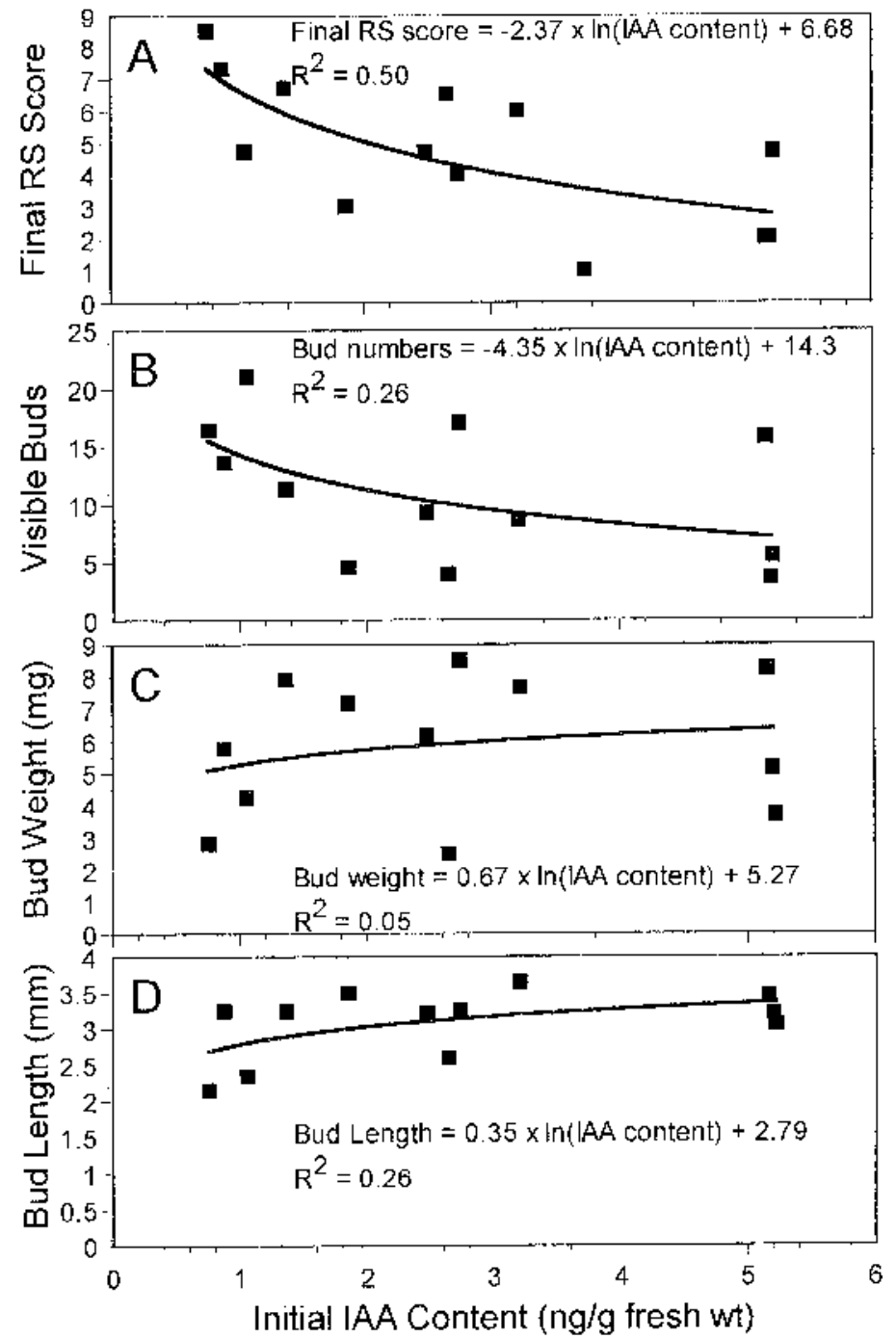

Fig. 3. Correlation between RS development after 8 days exposure to air +10 $\mu \mathrm{l} \cdot$ liter $^{-1}$ ethylene at $5 \mathrm{C}(\mathbf{A})$, number of visible axillary buds per head $(\mathbf{B})$, axillary bud weight $(\mathbf{C})$, and length (D) and initial (day 0) endogenous IAA content in Iceberg lettuce midrib segments. Leaves were scored visually for RS using a scale of $1=$ none to $9=$ very severe. 
Initial midrib IAA content of the different cultivars harvested from different fields and at different dates was not significantly correlated with the number of visible axillary buds per head (Fig. 3b), axillary bud weight (Fig. 3c), or length (Fig. 3d). Analyzing cultivars separately over different fields and harvest dates also did not show any significant correlations (data not shown). The number of visible axillary buds per head, axillary bud weight, and length also were not significantly correlated with final lettuce RS development across cultivars, growing conditions, and harvest dates (Fig. 4); $R^{2}$ values were all below 0.08. Analyzing cultivars separately across different fields and harvest dates also did not reveal any significant correlations (data not shown).

\section{Discussion}

$P A L$ and $R S$ development in RS-resistant and RS-susceptible cultivars. Iceberg lettuce cultivars that developed the most RS also developed the highest PAL activity (Fig. 1). Our data agree with those of Ke and Saltveit (1989a), who found that 'El Toro' and 'Calmar' were relatively RS resistant compared to 'Salinas' and
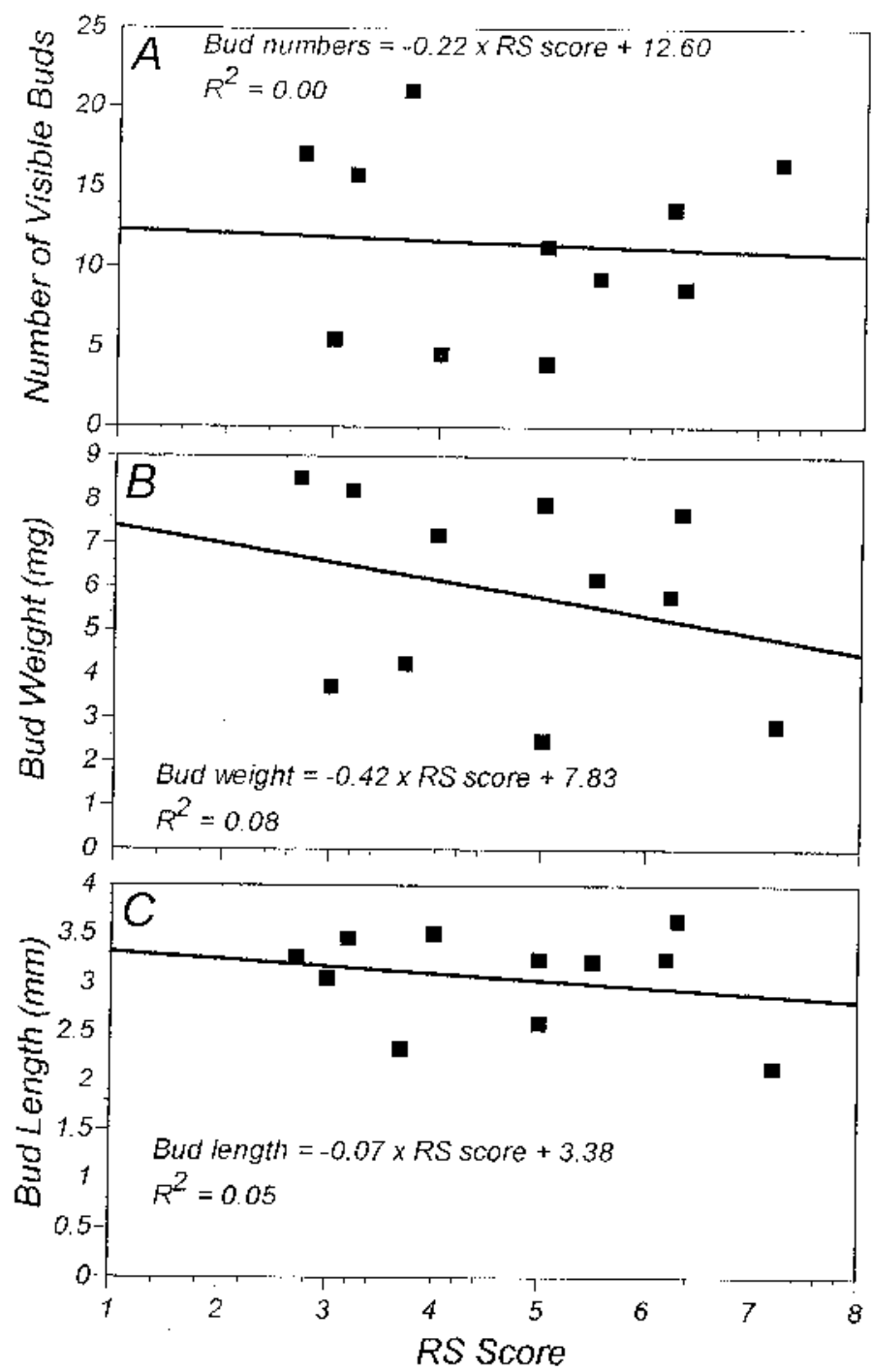

Fig. 4. Correlation between the number of visible axillary buds per head (A), axillary bud weight $(\mathbf{B})$, and length $(\mathbf{C})$ and RS development on Iceberg lettuce midrib segments after 8 days exposure to air $+10 \mu 1 \cdot$ liter $^{-1}$ ethylene at $5 \mathrm{C}$. Leaves were scored visually for RS using a scale of $1=$ none to $9=$ very severe. that their ethylene-induced PAL activity correlated well with their level of RS development. However, while they found 'Calmar' more RS resistant than 'El Toro,' we did not find any significant differences in RS susceptibility between the two cultivars. Their plants were grown in growth chambers while ours were grown in commercial fields. Since the degree of RS development is influenced by environmental growing conditions, the differences in growing environments could explain the differences in our results. We observed marked variation in RS developments from field to field. For example, after 8 days exposure to air + ethylene, 'Calmar' harvested from two different fields developed either no visible RS symptoms or a moderate RS score of 5 . We found good correlation between ethylene-induced PAL activity and RS development across different cultivars harvested from different fields. Our results agree with data previously published by other researchers (Hyodo et al., 1978; Ke and Saltveit, 1989b).

Endogenous free IAA content changes over time. Ke and Saltveit (1988) found that exposing Iceberg lettuce to ethylene stimulated ionically bound IAA oxidase activity. In our experiments, free IAA content decreased over 8 days whether tissues were exposed to ethylene or not (Fig. 2a). It is possible that ethylene-treated tissue reached low endogenous IAA levels more rapidly than nonethylene treated tissue, and that measuring IAA levels after 4 days would have revealed significantly lower IAA in ethylene-exposed tissue. In addition, IAA oxidase may not play as important a role in IAA oxidation as originally thought (Ernstsen et al., 1987; Lagrimini, 1991; Normanly et al., 1995). It is possible that ionically bound IAA oxidase in Iceberg lettuce does not play an important role in IAA degradation and that free IAA concentration is regulated primarily via other mechanisms (Reinecke, 1990; Tsurumi and Wada, 1990). It is clear, however, that free endogenous IAA decreases during storage. Thus, if endogenous IAA content was a major factor determining RS susceptibility, one would expect that after 8 days of storage RS-resistant cultivars such as 'El Toro' and 'Calmar' would become as susceptible as 'Salinas' and 'RC 74' since their free IAA levels were similar at that time. We have not, however, observed such similarity in susceptibility after 8 days storage in air (data not shown).

The amounts of endogenous IAA measured in Iceberg lettuce midribs were relatively low compared to the level reported in other plants and plant tissues. The highest free IAA level in Iceberg lettuce midribs was $5.2 \mathrm{ng} \cdot \mathrm{g}^{-1}$ fresh weight, while in vegetative tissue of corn (Zea mays L.), oat (Avena sativa L.), pea (Pisum sativum L.), and tobacco (Nicotiana tabacum L.) endogenous free IAA contents range from 18 to $35 \mathrm{ng} \cdot \mathrm{g}^{-1}$ fresh weight (Bandurski and Schulze, 1974, 1977; Thornburg and Li, 1991).

In our studies, 'RC 74' was the most RS-susceptible cultivar and developed significant RS after 8 days storage in air (Fig. 2b). There have been other observations of lettuce developing RS symptoms in the absence of exogenous ethylene (Lipton, 1961; Lipton et al., 1972). Healthy, nonstressed lettuce heads produce very little ethylene $\left(<0.01 \mu \mathrm{l} \cdot \mathrm{kg}^{-1} \cdot \mathrm{h}^{-1}\right)$. However, physical damage or pathogenic attack can greatly increase ethylene production (Morris et al., 1978). One of the fields of 'RC 74' was visibly stressed and under disease pressure from Sclerotinia minor. We did not use any visibly diseased or decaying lettuce heads, but biotic stresses in the field may have predisposed these susceptible plants to greater RS development. It is possible that the harvested heads of 'RC 74' were sensitive enough to be induced to form RS by trace amounts of harvesting-induced (wound) ethylene and ethylene present in the cold room. This may also explain the trace RS symptoms in 'RC 74' at the beginning of the experiment.

Free IAA content versus $R S$ development. Midrib tissue used for 
IAA analysis was evaluated for RS development just before freezing in liquid nitrogen so that IAA content and RS development could be compared. Our data indicated that normal physiological levels of endogenous IAA do not play a significant role in influencing RS susceptibility or resistance in Iceberg lettuce (Fig. 3a). Ke and Saltveit (1986) were able to significantly reduce RS development by treating Iceberg lettuce midrib segments with 0.1 or $1 \mathrm{~mm} 2,4-\mathrm{D}$ or with $1 \mathrm{~mm}$ IAA. It is likely that the amount of auxin infiltrated into the tissue was higher than that normally present, at least during the postharvest life of Iceberg lettuce. Such high concentrations could have inhibited RS development by effecting biochemical pathways not normally affected by physiological levels of IAA. It is possible that endogenous IAA content may potentially have some role in RS susceptibility during other stages of development not examined in our experiments.

Axillary bud development. Leaves, especially young leaves, are an important site of IAA biosynthesis. Free IAA produced in the leaf and transported to the stem should travel through the midrib. However, there was no significant correlation between endogenous IAA content and the number of axillary buds per head, their weight or length (Fig. 3 b-d). Even though there may be a relationship between IAA produced by the apical bud and axillary bud development, no relationship between leaf midrib IAA content and axillary bud development in Iceberg lettuce was apparent. In addition, although RS susceptibility and axillary bud development are under developmental control, the fact that they are not significantly correlated with each other suggests that they are not regulated directly by the same physiological factors. Thus, the underlying factors that determine RS susceptibility from cultivar to cultivar, head to head, and even cell to cell are still unidentified.

\section{Literature Cited}

Bandurski, R.S. and A. Schulze. 1974. Concentrations of indole-3-acetic acid and its esters in Avena and Zea. Plant Physiol. 54:257-262.

Bandurski, R.S. and A. Schulze. 1977. Concentration of indole-3-acetic acid and its derivatives in plants. Plant Physiol. 60:211-213.

California Department of Finance. California statistical abstract 1993. Calif. Dept. of Finance, Sacramento.

Camm, E.L. and G.H.N. Towers. 1973. Phenylalanine ammonia lyase. Phytochemistry 12:961-973.

Chen, K.H., A.N. Miller, G.W. Patterson, and J.D. Cohen. 1988. A rapid and simple procedure for purification of indole-3-acetic acid prior to GC-SIM-MS analysis. Plant Physiol. 86:822-825.

Cohen, J.D. 1984. Convenient apparatus for the generation of small amounts of diazomethane. J. Chromatogr 303:193-196.

Cohen, J.D., B.G. Baldi, and J.P. Slovin. 1986. ${ }^{13} \mathrm{C}_{6}$-[benzene ring]indole-3-acetic acid. A new internal standard for quantitative mass spectral analysis of indole-3-acetic acid in plants. Plant Physiol. 80:1419.

Ernstsen, A., G. Sandberg, and K. Lundström. 1987. Identification of oxindole-3-acetic acid, and metabolic conversion of indole-3-acetic acid to oxindole-3-acetic acid in Pinus sylvestris seeds. Planta 172:4752.

Hillman, J.R. 1986. Apical dominance and correlations by hormones, p. 341-349. In M. Bopp (ed.). Plant growth substances 1985. SpringerVerlag, Berlin.
Hyodo, H., H. Kuroda, and S.F. Yang. 1978. Induction of phenylalanine ammonia-lyase and increase in phenolics in lettuce leaves in relation to the development of russet spotting by ethylene. Plant Physiol. 62:31-35.

Ke, D. and M.E. Saltveit. 1986. Effects of calcium and auxin on russet spotting and phenylalanine ammonia-lyase activity in iceberg lettuce. HortScience 21:1169-1171.

Ke, D. and M.E. Saltveit. 1988. Plant hormone interaction and phenolic metabolism in the regulation of russet spotting in iceberg lettuce. Plant Physiol. 88:1136-1140.

Ke, D. and M.E. Saltveit. 1989a. Developmental control of russet spotting, phenolic enzymes, and IAA oxidase in cultivars of iceberg lettuce. J. Amer. Soc. Hort. Sci. 114:472-477.

Ke, D. and M.E. Saltveit. 1989b. Regulation of russet spotting, phenolic metabolism, and IAA oxidase by low oxygen in iceberg lettuce. J. Amer. Soc. Hort. Sci. 114:638- 642.

Ke, D. and M.E. Saltveit. 1989c. Wound-induced ethylene production, phenolic metabolism and susceptibility to russet spotting in iceberg lettuce. Physiol. Plant. 76:412-418.

Koukol, J. and E.E. Conn. 1961. The Metabolism of aromatic compounds in higher plants. IV. Purification and properties of the phenylalanine deaminase of Hordeum vulgare. J. Biol. Chem . 236:2692-2698.

Lagrimini, L.M. 1991. Peroxidase, IAA oxidase and auxin metabolism in transformed tobacco plants (Abstr. 497). Plant Physiol. 96:S-77.

Link, G.E. and M.W. Gardner. 1919. Market disease of vegetables. Phytopathology 9:497-520.

Lipton, W.J. 1961. Anatomical observations on russet spotting and pink rib of lettuce. Proc. Amer. Soc. Hort. Sci. 78:367-374.

Lipton, W.J. 1967. Market quality and rate of respiration of head lettuce held in low-oxygen atmospheres. U.S. Dept. Agr. Mktg. Res. Rpt. 777.

Lipton, W.J., J.K. Stewart, and T.W. Whitaker. 1972. An illustrated guide to the identification of some market disorders of head lettuce. U.S. Dept. Agr. Mktg. Res. Rpt. 950.

Moline, H.E. and W.J. Lipton. 1987. Market diseases of beets, chicory, endive, escarole, globe artichokes, lettuce, rhubarb, spinach, and sweetpotatoes. U.S. Dept. Agr., Agr. Hndbk. 155, 86 p.

Morris, L.L., A.A. Kader, J.A. Klaustermeyer, and C.C. Cheyney. 1978. Avoiding ethylene concentrations in harvested lettuce. Calif. Agr. 32(6):14-15.

Morris, L.L., J.A. Klaustermeyer, and A.A. Kader. 1974. Postharvest requirements of lettuce to control physiological disorders. Proc. 26th Intl. Conf. Handling Perishable Agr. Comm. p. 22-29.

Normanly, J., J.P. Slovin, and J.D. Cohen. 1995. Rethinking auxin biosynthesis and metabolism. Plant Physiol. 107:323-329.

Reinecke, D.M. 1990. The oxindole-3-acetic acid pathway in Zea mays, p. 367-373. In R.P. Pharis and S.B. Rood (eds.). Plant growth substances 1988. Springer-Verlag, Berlin.

Rood, P. 1956. Relation of ethylene and postharvest temperature to brown spot of lettuce. Proc. Amer. Soc. Hort. Sci. 68:296-303.

Thornburg, R.W. and X. Li. 1991. Wounding Nicotiana tabacum leaves causes a decline in endogenous indole-3-acetic acid. Plant Physiol. 96:802-805.

Tsurumi, S. and S. Wada. 1990. Oxidation of indole-3-acetylaspartic acid in Vicia, p. 353-359. In R.P. Pharis and S.B. Rood (eds.). Plant growth substances 1988. Springer-Verlag, Berlin.

U.S. Department of Agriculture. 1994. California vegetable review. Stat. Rpt. Serv., Sacramento, Calif.

White, J.C., G.C. Medlow, J.R. Hillman, and M.B. Wilkins. 1975. Correlative inhibition of lateral bud growth in Phaseolus vulgaris $\mathrm{L}$. Isolation of indole acetic acid from the inhibitory region. J. Expt. Bot. $26: 419-24$ 